\title{
Impactos da poluição atmosférica no processo de polinização das abelhas: cidade do Rio de Janeiro
}

As abelhas são consideradas de extrema importância para a manutenção da vida no planeta, sobretudo devido a sua contribuição e responsabilidade no processo de polinização de ecossistemas agrícolas e naturais. Todavia, estudos indicam a diminuição da população em espécies de abelhas em todo o planeta, relacionando tal fato com a poluição atmosférica, principalmente pelo aumento nos níveis de óxidos de nitrogênio (NOx), tendo como principal causa as emissões veiculares. Deste modo, o presente trabalho tem como principal objetivo estudar os possíveis impactos ambientais oriundos dos níveis de NOx sobre o processo de polinização das abelhas na cidade do Rio de Janeiro. A metodologia utilizada se deu por meio de levantamento bibliográfico acerca da problemática que envolve o processo de polinização das abelhas, bem como sobre a tomada de dados a respeito da concentração de dióxido de nitrogênio (NO2) para a cidade do Rio de Janeiro e fatores que pode prejudicar a polinização eficiente na região. Ao término dessa pesquisa foi possível constatar a carência de estudos relacionados à influência direta dos gases NOx sobre a vegetação, bem como sobre o seu impacto na polinização das abelhas. Vale ressaltar, que este trabalho procurou apontar como esse assunto é importante e urgente, sugerindo necessidade de monitoramento destes gases, bem como ações para uma maior preservação das espécies, tais como a educação ambiental e estímulo na criação de abelhas sem ferrão.

Palavras-chave: Óxidos de Nitrogênio; Abelhas; Polinização; Angiospermas.

\section{Impacts of air pollution on the bee pollination process: city of Rio de Janeiro}

\begin{abstract}
Bees are considered extremely important for the maintenance of life on the planet, mainly due to their contribution and responsibility in the process of pollination of agricultural and natural ecosystems. However, studies indicate the decrease of the population in bee species throughout the planet, relating this fact to air pollution, mainly due to the increase in nitrogen oxide (NOx) levels, having as main cause vehicular emissions. Thus, the main objective of this work is to study the possible environmental impacts arising from NOx levels on the bee pollination process in the city of Rio de Janeiro. The methodology used was through a bibliographic survey about the problem that involves the pollination process of bees, as well as on the taking of data on the concentration of nitrogen dioxide (NO2) for the city of Rio de Janeiro and factors that can impair efficient pollination in the region. At the end of this research, it was possible to observe the lack of studies related to the direct influence of NOx gases on vegetation, as well as on their impact on bee pollination. It is noteworthy that this work sought to point out how important and urgent this issue is, suggesting the need for monitoring these gases, as well as actions for greater preservation of species, such as environmental education and stimulation in the creation of stingless bees.
\end{abstract}

Keywords: Nitrogen Oxides; Bees; Pollination; Angiosperms.

Topic: Conservação da Biodiversidade

Reviewed anonymously in the process of blind peer
Received: 04/03/2021

Approved: 23/03/2021
Gisele Palmares Gomes da Paixão

Universidade Veiga de Almeida, Brasil

http://lattes.cnpq.br/9261663705759875

gisele.palmares@yahoo.com.br

Cleyton Martins da Silva (it

Universidade Veiga de Almeida, Brasil

http://lattes.cnpq.br/2637457192603373

http://orcid.org/0000-0002-5216-4977

cleyton.silva@uva.br 


\section{INTRODUÇÃO}

A polinização é um serviço ecossistêmico essencial para a reprodução e manutenção da diversidade de espécies de plantas, além de fornecer alimentos para humanos e animais (FREITAS et al., 2015). O processo de polinização pode ser realizado de forma direta (autopolinização) ou indireta (cruzada). Ao ser efetuada a polinização cruzada, se permite a variabilidade genética, ou seja, um procedimento mais vantajoso (RECH et al., 2014). Para que ocorra a polinização cruzada, é necessária a presença de um agente polinizador (componentes bióticos ou abióticos). Ele é o responsável pela transferência do pólen entre as partes masculinas e femininas da flor.

Dentre as muitas espécies (componentes bióticos) que realizam a polinização, tais como: vespas, borboletas, pássaros, pequenos mamíferos e morcegos, destacam-se as abelhas como os principais agentes polinizadores dos vegetais (NASCIMENTO, 2012). Diferente dos demais grupos, insetos ou não, as abelhas se alimentam exclusivamente de pólen e néctar e precisam visitar diariamente uma grande quantidade de flores para suprir suas necessidades individuais (FREITAS et al., 2015), de suas crias em desenvolvimento e, no caso das espécies sociais, armazenar alimento, principalmente para o período de escassez de flores.

Desse modo, o trabalho das abelhas é tido como um serviço ecológico-chave para a manutenção e a conservação dos ecossistemas (ZATELLI, 2019). E assim sendo, possuem papel estratégico na reconstituição de florestas tropicais e conservação de remanescentes florestais.

No tempo em que a importância da polinização vem se tornando cada vez mais evidente, visto que a demanda por alimentos é diretamente proporcional ao aumento da população, estudos indicam que a população de abelhas está em declínio (FREITAS et al., 2015). Existe uma combinação de fatores que influenciam no desaparecimento ou migração desses agentes polinizadores, como a perda de habitat natural, as mudanças climáticas e as más práticas agrícolas. Em destaque, a redução de áreas florestais tornando-se consequência da emancipação das cidades.

Nesse mesmo contexto, estudos ainda sugerem que o declínio na população das abelhas poderia estar associado ao aumento na concentração de determinados poluentes atmosféricos (GIRLING et al., 2013), que tem sido intensificado pela crescente industrialização e urbanização, sobretudo em grandes centros urbanos, que passaram a ser pautas de estudos, no que dizem respeito à poluição atmosférica e principalmente aquelas oriundas de veículos automotores, sendo estas, uma das formas responsáveis pela degradação do meio ambiente e qualidade de vida das populações (DANTAS et al., 2020; SICILIANO et al., 2018; SILVA et al., 2018).

Na Cidade do Rio de Janeiro não é diferente, situada a 2254'23" de latitude sul e 4310'21" de longitude oeste, no município do mesmo nome: é a capital do Estado do Rio de Janeiro (RIOTUR, 2009), onde se concentrava uma população estimada de 6.718 .903 habitantes em 2019, com uma área de 1.200,255 km2 (IBGE, 2019). Adicionalmente, dados do Instituto Brasileiro de Geografia e Estatística mostram que até o ano de 2018 existiam cerca de 2.827.516 veículos automotores na cidade (IBGE, 2018).

Diferentes poluentes são emitidos por veículos automotores, tais como: monóxido de carbono (CO), 
hidrocarbonetos não metano (NMHC), material particulado (MP), aldeídos (RCHO), óxidos de enxofre (SOx), e óxidos de nitrogênio (NOx), tanto na cidade do Rio de Janeiro quanto em outros centros urbanos (SICILIANO et al., 2019; SILVA et al., 2018).

No que diz respeito aos poluentes atmosféricos citados, destaca-se o NOx (óxidos de nitrogênios), sendo uma classe de compostos tóxicos às plantas (PEDROSO, 2007), visto que afeta a redução da permeabilidade das membranas celulares, impedindo as trocas gasosas das folhas e prejudicando a realização da fotossíntese (ECYCLE, 2020). Em continuidade, o NOx degrada determinados compostos químicos presentes no perfume das flores, prejudicando assim, a habilidade que as abelhas têm de reconhecer o aroma.

Entretanto, apesar da relevância do tema, poucos estudos sugerem a associação da concentração deste com a atividade de polinização das abelhas, sendo mais relevante ainda no cenário em que a cidade do Rio de Janeiro está contida, visto que é detentora das maiores florestas urbanas primárias e secundárias do mundo, o Parque Estadual da Pedra Branca e a Floresta da Tijuca, respectivamente.

Por se tratar de um tema bastante relevante, o presente artigo buscou compreender as concentrações de $\mathrm{NOx}$, em especial o $\mathrm{NO}_{2}$, na cidade do Rio de Janeiro e como esse processo pode influenciar na diminuição de população de abelhas e consequentemente no processo de polinização.

\section{METODOLOGIA}

A pesquisa desenvolvida buscou uma abordagem exploratória, sendo realizada inicialmente uma revisão sistemática na literatura, de modo a analisar, recuperar e criticar diferentes documentos e estudos primários da literatura (PEREIRA et al., 2014), com a expectativa de compreender os principais conceitos referentes ao processo de polinização realizado pelas abelhas, bem como a importância do serviço ecossistêmico proporcionado por este processo em diferentes cenários, e ainda discutir os possíveis interferentes antrópicos neste processo.

Em continuidade, uma revisão bibliográfica permitiu caracterizar a cidade do Rio de Janeiro, local de estudo deste trabalho, consentindo a compreensão geográfica da cidade, assim como a aquisição de dados referentes às concentrações de poluentes atmosféricos, sobretudo o $\mathrm{NO}_{2}$. Neste âmbito, a pesquisa assume um caráter quali-quantitativo, quando fundamenta e valida evidências a partir da obtenção e discussão de dados mensuráveis (FREITAS et al., 2011).

\section{DISCUSSÃO TEÓRICA}

Num arcabouço teórico, a polinização é a transferência de grãos de pólen entre órgãos masculinos e femininos das flores, tornando-se um processo importante para a reprodução das plantas que resultam na formação de frutos e sementes (KLINKHAMER et al., 1994). A polinização é realizada tanto por animais como por vento ou água (FREITAS et al., 2015). Admite-se que entre as 250 mil espécies de plantas com flores (angiospermas), 90\% são polinizadas por animais, principalmente, por diversas ordens de insetos (KEARNS et al., 2000). Os insetos polinizadores possuem estruturas corporais que auxiliam no transporte do pólen, 
enorme capacidade reprodutiva, aparelho bucal adaptado ao tipo de flor em busca seu alimento (BUCHMANN et al., 1996). Muitos insetos são altamente especializados visitando unicamente um tipo de flor ( $\mathrm{NUCCl}, 2016)$. Outros, porém, são generalistas e capazes de buscar sua fonte alimentar em diversas espécies de flores (MORALES et al., 2008).

Foi identificada, uma interação e/ou relação mutualística, onde as plantas efetuam sua reprodução com mais eficiência enquanto os insetos polinizadores retiram dos vegetais o seu alimento (GULLAN et al., 2007). Pode-se destacar o comportamento das abelhas nessa atividade, visto que, são dependentes das flores para a obtenção de alimento (néctar, pólen, óleo) e outros recursos, tais como: fragrâncias, resinas, tricomas florais e calor (WILLIAMS et al., 1972; SIMPSON et al., 1981). Além disso, as flores podem servir como local para cópula e repouso para algumas espécies de abelhas (FAEGRI et al., 1979; SIMPSON et al., 1981). Diante disso, acredita-se que abelhas e as plantas angiospermas coevoluíram mutuamente ao longo do tempo evolutivo, num processo que beneficiou ambos os grupos envolvidos (DEL CLARO et al., 2012).

Através de estudos, foi possível afirmar que as abelhas são os polinizadores mais importantes para a reprodução da maior parte das angiospermas (ROUBIK, 1989). Ademais, a diversidade presente no grupo das abelhas e as adaptações morfológicas (estruturas de coleta e transporte) (SILVEIRA et al., 2002), fisiológicas (metabolismo) (ROUBIK, 1989) e comportamentais (sincronização com eventos florais e memória temporal) melhoram localização e a exploração dos recursos florais (SAUNDERS, 1982; MOORE, 2001).

Ecologicamente, a maioria das espécies vegetais, incluindo grande parte das plantas cultivadas, não apresenta autopolinização e tampouco é passível de frutificação na ausência de polinizadores (WOLOWSKI et al., 2019). Nesse caso, através polinização, a transferência de pólen entre diferentes indivíduos de plantas da espécie (polinização cruzada) pode melhorar a qualidade dos frutos e sementes produzidos e ampliar a variabilidade genética (NASCIMENTO, 2012). Esse processo resulta na base de toda uma cadeia alimentar. A polinização das abelhas é um serviço ambiental que permite a manutenção da biodiversidade, além de ser essencial para a produção de diversos alimentos (CGEE, 2017).

Dentre os serviços ecossistêmicos, a abelha social Apis mellifera e as abelhas nativas sem ferrão predominam nos registros como visitantes florais e polinizadores de cultivos relacionados à produção de alimentos (WOLOWSKI et al., 2019). Em virtude disso, com o objetivo de explorar com segurança e mais praticidade todos os benefícios, no Brasil tem aumentado, cada vez mais, o número de criadouros de abelhas sem ferrão (VENTURIERI et al., 2017). Infelizmente a implementação relacionada a projetos que visam à conservação das abelhas, colide com as principais ameaças que esses insetos sofrem, como gases poluentes.

Embora o Nitrogênio seja um elemento importante para a existência da vida na Terra, formação das proteínas e das bases nitrogenadas que compõem os ácidos nucleicos, o DNA e o RNA. Além de assimilado por bactérias para criar diversas formas diferentes e assim ser absorvido pelas plantas e animais. Existe a participação de dois compostos dos Óxidos de nitrogênio (NOx) que são considerados poluentes primário, relevantes no que se refere à poluição atmosférica: $\mathrm{O}$ óxido nítrico $(\mathrm{NO})$ e o dióxido de nitrogênio $\left(\mathrm{NO}_{2}\right)$ (CÓNSUL et al., 2004), que através de reações químicas complexas junto a compostos orgânicos voláteis, na presença de radiação solar, formam o poluente secundário Ozônio $\left(\mathrm{O}_{3}\right)$. Os NOx são oriundos 
majoritariamente da combustão de combustíveis fósseis, em especial no que diz respeito às emissões veiculares. São considerados compostos fitotóxicos e inibem o crescimento de vegetais (FROTA et al., 2019). Um estudo realizado pela Universidade de Southampton, do Reino Unido aponta que os odores florais são fundamentais para que o inseto localize, identifique e reconheça a planta da qual ele extrai o néctar (GIRLING et al., 2013). A queima de diesel lança poluentes na atmosfera que podem afetar a capacidade das abelhas de reconhecerem o cheiro das flores.

Ainda de acordo com Girling et al. (2013), a exposição a uma mistura em proporção de 1:1 de NO + $\mathrm{NO}_{2}$, e em uma concentração de aproximadamente $10 \mathrm{ppm}\left(18.814 \mathrm{\mu g} / \mathrm{m}^{3}\right)$ de cada um dos ditos gases, determinados compostos, tais como o $\alpha$-terpineno, $\alpha$-farneseno e fenilacetaldeído (importantes contribuintes do odor de determinadas espécies de flores), tiveram suas concentrações diminuídas a níveis indetectáveis.

Em outro experimento, os autores também relatam que em exposições a níveis ainda menores, tais como $0,1 \mathrm{ppb}\left(188,14 \mathrm{\mu g} / \mathrm{m}^{3}\right)$, quatro dos oito compostos da mistura odorífera já apresentam reduções consideráveis. Cabe ressaltar que níveis de 0,1 ppm (100 ppb) são utilizados frequentemente para a determinação da qualidade do ar ambiental, e que, desta forma, pode-se associar tal exposição como sendo também prejudicial ao processo de polinização das abelhas, devido a alterações no odor exalado pelas flores.

Em outro estudo, realizado pela Universidade Estadual Paulista - UNESP, foi possível reforçar a concepção de que o ar poluído com $\mathrm{NO}_{2}$ pode afetar indiretamente a ecologia vegetal, uma vez que ele é precursor do $\mathrm{O}_{3}$ (Ozônio). Os danos causados por esse poluente são:

Pontuações de coloração diferenciada, que podem ser necroses, cloroses ou se apresentar como manchas variegadas. Esses sintomas são resultantes dos seguintes eventos: interação do ozônio com alguns componentes da célula do tecido foliar; colapso da célula e água concentrada na vizinhança da interação; branqueamento da clorofila dentro da célula injuriada; colapso da estrutura foliar em torno da célula danificada. Esse fotoxidante penetra nos espaços intercelulares e reage com compostos bioquímicos da parede celular e da membrana plasmática, desencadeando a formação de lesões necróticas foliares em casos de exposição aguda ou a senescência acelerada em casos de exposição crônica ao poluente. Em nível celular, segundo o conceito de interação célula-célula dentro da folha, a morte da célula conduz, rapidamente, morte de muitas células vizinhas (efeito amplificado). Tal fato deve-se ao desbalanço íon-água. O rombo produzido pelo ozônio em uma célula, com perda de água e de pressão, pode 'sugar' a água das células vizinhas, através do plasmodesmo, causando injúrias em efeito cascata. (CETESB, 2020)

Através de amostragem atmosférica, isto é, em rodovias com tráfegos constituídos por veículos leves e pesados, próximos ao Instituto de Química da UNESP em Araraquara-SP, foram observados valores médios de concentração de $\mathrm{NO}_{2}$ na ordem de $7,1 \pm 2,8 \mathrm{ppb}(\mathrm{n}=55)$ ao longo do dia. $\mathrm{O}$ estudo ainda sugere que os processos fotoquímicos são os principais mecanismos para remoção de $\mathrm{NO}_{2}$ da atmosfera com formação de produtos secundários, como $\mathrm{O}_{3}$ (UGUCIONE et al., 2009). O valor de $40 \mathrm{ppb}$ de ozônio $\left(78,4 \mu \mathrm{g} / \mathrm{m}^{3}\right.$.h) é citado, por diversos autores, como aquele a partir do qual injúrias podem ocorrer nas plantas de clima temperado (CETESB, 2020).

Assim sendo, os resultados obtidos nos estudos da Universidade de Southampton e UNESP são de extrema relevância e podem ser considerados para o cenário da cidade do Rio de Janeiro, visto que este município é considerado uma área de grande mobilidade urbana, e com elevada frota de veículos 
automotores, em concomitância coma a sua extensa área verde, completamente inserida no bioma Mata Atlântica.

A Mata Atlântica é rica em biodiversidade ambiental (ARAÚJO, 2015), criando as condições adequadas para a evolução de um complexo biótico de natureza vegetal e animal altamente abundante (APREMAVI, 2020). As espécies deste bioma estão entrelaçadas em uma rede complexa de interdependência, o desaparecimento de uma planta do grupo das angiospermas (vegetais que apresentam suas sementes protegidas dentro de frutos) ou animal, como as abelhas, compromete as condições de vida de vários outros seres. Na figura 2 é representado mapa de cobertura vegetal (área verde) das florestas do bioma de Mata Atlântica da cidade do Rio de Janeiro.

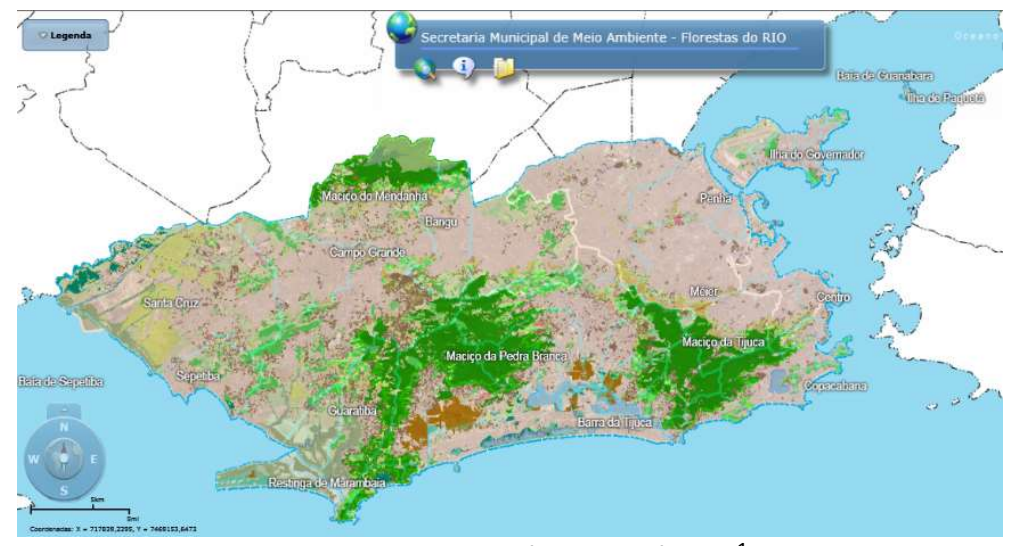

Figura 1: Sistema Florestas do Rio ${ }^{1}$.

Áreas verdes urbanas do município do Rio de Janeiro, estão associadas aos espaços livres, sistema de áreas verdes, arborização urbana, florestas urbanas e infraestrutura verde (PEDREIRA et al., 2017). Apesar disso, a cidade possui total ou parcialmente dentro de seu território três maciços costeiros com expressiva cobertura florestal, onde estão situados um parque nacional (Parque Nacional da Tijuca), quatro parques estaduais (Parque Estadual da Pedra Branca; Parque Estadual do Grajaú; Parque Estadual da Chacrinha; Parque Estadual do Mendanha), diversos parques naturais municipais e parques urbanos, projetos de reflorestamento em desenvolvimento, farta arborização urbana em vias e praças, além de áreas com atividade agrícola tradicional.

Por outro lado, a atividade humana e sua concentração em assentamentos urbanos vêm sendo associadas a um progressivo aumento da degradação do meio ambiente (MAIA et al., 2019).

Ao longo do tempo, os veículos a diesel foram mais criticados por suas emissões de partículas, que ficam suspensas no ar e são consideradas cancerígenas pela Organização Mundial da Saúde (OMS). Desde então, houve avanços nesse aspecto, embora os novos filtros de partículas, associados a um catalisador, tenham provocado um aumento das emissões de NOx (MINAS GERAIS, 2015).

A poluição atmosférica é um dos problemas ambientais crônicos das grandes metrópoles, sua composição química é um grande desafio para muitos pesquisadores que buscam identificar quais são os riscos desses poluentes lançados na natureza todos os dias (MACEDO, 2018).

${ }^{1}$ http://sigfloresta.rio.rj.gov.br 
No Rio de Janeiro três órgãos públicos dispõem de uma rede de estações meteorológicas que incluem aferição de poluentes e ajudam a fazer o controle e a classificação da qualidade do ar na cidade: Instituto Estadual do Ambiente (INEA), Secretaria Municipal de Meio Ambiente (SMAC) e Instituto Nacional de Meteorologia (INMET).

O presente estudo valeu-se sobre o monitoramento realizado pela Secretaria Municipal de Meio Ambiente (SMAC). Esse monitoramento tem como objetivo identificar os poluentes, quantificá-los e apontar quais os efeitos nocivos presentes. Além de garantir o desenvolvimento socioeconômico sustentável e ambientalmente seguro com a prevenção, combate e redução das emissões dos poluentes, conforme figura 2.

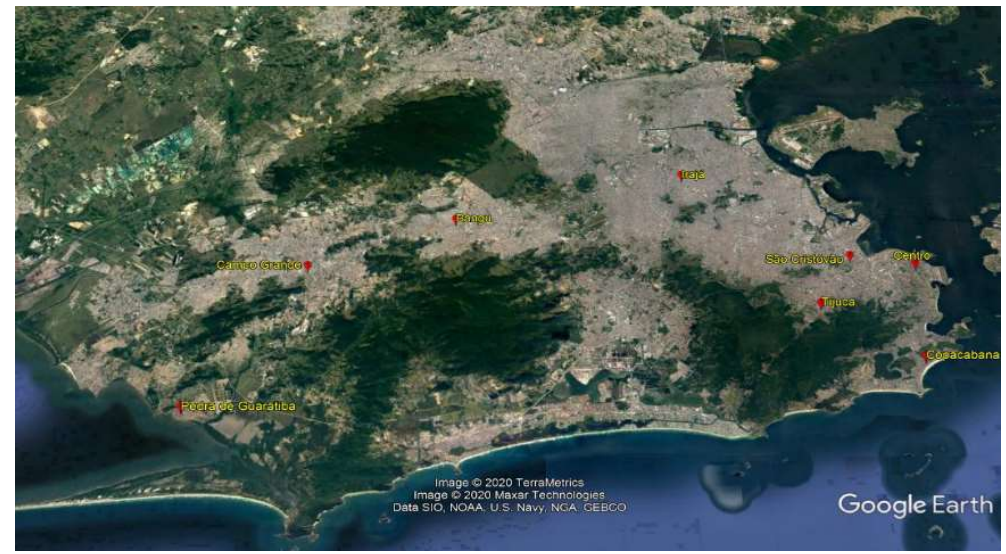

Figura 2: Orientação espacial dos bairros que fazem parte do Programa de Monitoramento da Qualidade do ar da prefeitura da cidade do Rio de Janeiro. Fonte: Google Earth (2020).

É realizado monitoramento de forma constante e concisa a respeito do diagnóstico de qualidade do ar, nos bairros de: Bangu, Campo Grande, Centro, Copacabana, Guaratiba, Irajá, São Cristóvão e Tijuca da Cidade do Rio de Janeiro. São enviados dados para o banco de monitoramento (Secretaria de Meio Ambiente da Cidade do Rio de Janeiro), por telemetria.

Os boletins são atualizados diariamente e o acesso aos dados já tratados e público, com opções de dados anteriores. Contudo, as informações do significado das classificações dos gases poluentes limitam-se aos efeitos dos mesmos a saúde humana, ou seja, não há informação sobre os possíveis efeitos dos contaminantes a flora e fauna. Tendo como exemplo, classificação Regular que se refere as pessoas de grupos sensíveis (crianças, idosos e pessoas com doenças respiratórias e cardíacas) podem apresentar sintomas como tosse seca e cansaço. A população, em geral, não é afetada.

Diante disso, considerando-se o cenário do Rio de Janeiro, no que diz respeito à sua significativa frota veicular e emissões atmosféricas, em consonância com a presença de extensas áreas verdes, tomou-se os dados referentes aos níveis de concentração de $\mathrm{NO}_{2}$ para diferentes bairros da cidade próximos a extensas áreas verdes, permitindo uma inferência sobre as concentrações de NOx, devido ao seu equilíbrio com o NO $\left(2 \mathrm{NO}+\mathrm{O}_{2} \rightarrow 2 \mathrm{NO}_{2}\right.$ ), podendo ser um indicativo acerca dos impactos sobre a vegetação.

A Figura 3 representa um gráfico elaborado a partir da média mensal dos valores máximos de concentração diária de $\mathrm{NO}_{2}$, referentes ao período de 22/09/2019 a 22/12/2019 (estação da primavera), nas estações: Tijuca, próxima ao Parque Nacional da Tijuca - PNT; Bangu e Campo Grande, fronteiriça ao Parque 
Estadual da Pedra Branca - PEPB, sendo estas áreas escolhidas devido as suas proximidades com as extensas áreas verdes citadas.

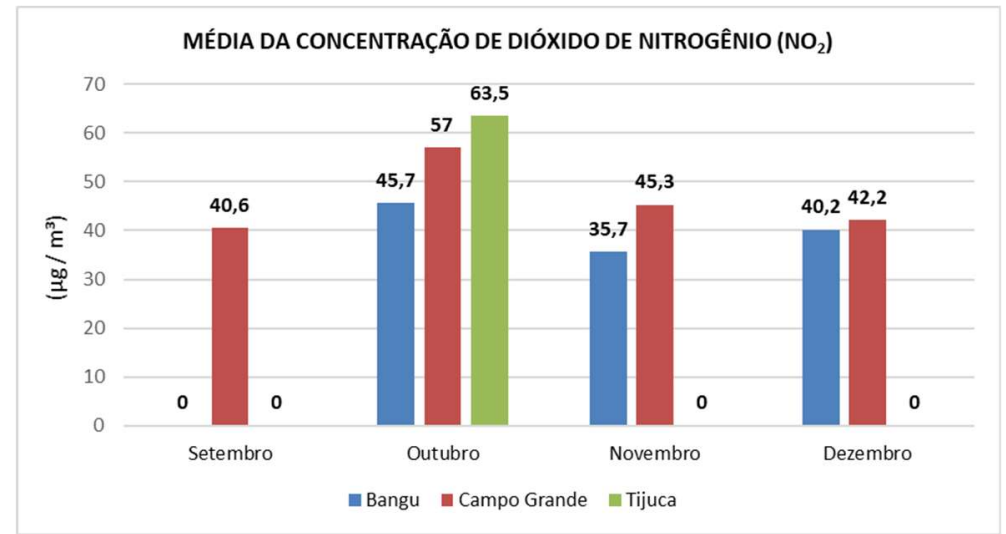

Figura 3: Média de concentração de NO2 no período da primavera do ano de 2019.

O sistema de Boletins de Qualidade do Ar, não disponibilizou os valores de concentração máxima de $\mathrm{NO}_{2}$, nas estações da Tijuca e Bangu, mês de setembro (dia 22 a 30), sendo disponibilizado, somente, a numeração da estação de Campo Grande, com a média de 46,6 $\mu \mathrm{g} / \mathrm{m}^{3}$; No mês de outubro (dia 1 a 31 ) foi possível coletar alguns valores diários das concentrações de todas as estações, sendo: Bangu com média de 45,7 $\mu \mathrm{g} / \mathrm{m}^{3}$, Campo Grande $57 \mu \mathrm{g} / \mathrm{m}^{3}$ e Tijuca com 63,5 $\mu \mathrm{g} / \mathrm{m}^{3}$; Em novembro (dia 1 a 30) foi permitido obter o valor das estações de Bangu com aproximadamente $35,7 \mu \mathrm{g} / \mathrm{m}^{3}$ e Campo Grande com 45,3 $\mu \mathrm{g} / \mathrm{m}^{3}$. Na estação da Tijuca os dados não foram disponibilizados. Em dezembro (até o dia 21) a estação de Bangu ficou com a média de 40,2 $\mu \mathrm{g} / \mathrm{m}^{3}$ e estação de Campo Grande com 42,2 $\mathrm{\mu g} / \mathrm{m}^{3}$. Na estação da Tijuca os dados não foram disponibilizados.

Com os resultados das médias da concentração de $\mathrm{NO}_{2}$ representados na figura 3, foi permitido uma avaliação dos valores em micrograma/metros cúbicos $\left(\mu \mathrm{g} / \mathrm{m}^{3}\right)$ de cada estação, além de realizar uma análise mais segura sobre provável interferência desses valores, em longo prazo, no Parque Nacional da Tijuca e Parque Municipal da Pedra Branca.

Foi observado, também, que os níveis de concentração do presente gráfico não ultrapassam os valores experimentados na pesquisa da Universidade de Southampton $\left(188,14 \mu \mathrm{g} / \mathrm{m}^{3}\right)$, porém é possível que a exposição prolongada a níveis ainda que menores prejudiquem consideravelmente o processo de polinização.

Os valores utilizados como orientadores foram assim aplicados por insuficiência de dados brasileiros. Dessa forma, é de extrema importância que estudos relacionados a temática do presente trabalho sejam estimulados, visto que o Brasil é representado pela variedade de biomas e enorme riqueza da flora e da fauna. A cidade do Rio de Janeiro é um exemplo disso, ocupada pela Mata Atlântica, sendo simultaneamente um dos ecossistemas mais ricos em biodiversidade e mais ameaçados do planeta.

O PNT é a maior floresta urbana do mundo, com 3.953 hectares de Mata Atlântica. Apresentando uma biodiversidade significativa, com 1619 espécies vegetais, sendo que destas, 433 estão ameaçadas de extinção. Além de possuir uma fauna relevante tanto de invertebrados quanto de vertebrados. Os animais 
invertebrados, dessa região, possuem um importante papel no ecossistema, contribuindo para a decomposição de matéria orgânica e a ciclagem de nutrientes, realizando a polinização das plantas para produção de frutos e atuando como elementos fundamentais na cadeia alimentar. Sua importância excede ao caráter recreacionista, tendo em vista o seu fundamental papel no fornecimento de serviços ambientais para a população da cidade do Rio de Janeiro, destacando-se na redução da poluição atmosférica (IBASE, 2006). Ademais, segundo um estudo realizado pela a PUC-Rio, a floresta da Tijuca absorve os metais pesados despejados pelo trânsito de veículos que transpõe a região, tornando o ar mais impoluto.

No PEPB é apresentado um conjunto de características importantes para a conservação da flora e fauna, por exemplo: elevada diversidade da flora e número de espécies endêmicas, raras e ameaçadas, e existência de centenas de espécies de insetos (FEMERJ, 2011). Porém, assim como no PNT, existe a presença de estradas com movimentação elevada de veículos automotores, que cortam o PEPB, dentre elas: Avida das Américas e Estrada do Grumari.

No que diz respeito os níveis de poluentes atmosféricos, em especial os NOX, estudos revelam que, para que sejam reduzidas as emissões de óxidos de nitrogênio provenientes de veículos, podem ser aplicados métodos de aperfeiçoamento em motores e catalisadores. Assim como, investimento em Planejamento Urbano e tecnologia, sobretudo no que diz respeito à mobilidade, visto que utilização de diesel para veículos pesados (ônibus e caminhões) seriam os principais emissores destes compostos.

Adicionalmente, observa-se que, a atualização por meio de sucessivas resoluções do Conselho Nacional do Meio Ambiente (CONAMA), para alinhar o desenvolvimento tecnológico da engenharia automotiva refere a veículos leves e pesados (AFEEVAS, 2016), são importantes para aumentar o rigor no controle da emissão de óxidos de nitrogênio em veículos a diesel.

Enfatizando essas alternativas, a mitigação na emissão desses poluentes, e consequente diminuição dos níveis de concentração na atmosfera, podem trazer grandes benefícios para o meio ambiente, sobretudo, na atividade de polinização das abelhas.

Entretanto, cabe ainda discutir que, as abelhas são insetos geralmente rejeitados pelos indivíduos, mesmo quando as espécies não possuem ferrão. Por isso, é recorrente ver pessoas atearem fogo nos enxames, sem saber que as abelhas são fundamentais para a manutenção de várias espécies florais (LORENZON, 2006).

De acordo com pesquisas:

No Brasil, existem várias de espécies de abelhas. O destaque é para o gênero Melipona, as abelhas sem ferrão. Diferentemente das abelhas do gênero Apis, introduzidas no Brasil em 1838, animal exótico e perigoso (sua picada pode matar), as Meliponas não apresentam risco e, após milhões de anos de evolução, estão mais bem adaptadas ao meio. (MEIRELLES FILHO, 2017)

Mas especialistas acreditam que, num futuro bem próximo, somente dez espécies poderão ser salvas da extinção (LORENZON, 2006).

As abelhas sem ferrão são conhecidas por uruçu, jataí, mandaçaia e etc. representam imenso e pouco conhecido patrimônio brasileiro (MEIRELLES FILHO, 2017). Em razão disso, alguns projetos de criação de abelhas sem ferrão foram executados, como no Jardim Botânico e em Ilha Grande, na bacia de Angra dos 
Reis, ambos no Rio de Janeiro. Esses projetos buscam a preservação de espécies, educação ambiental, renda extra para a comunidade, prevenção a extinção de vegetais e aumentar a produtividade de plantas cultivadas (RAMALHO, 2006; GRANDA, 2016).

No projeto realizado pela Universidade Federal Rural do Rio de Janeiro (UFRRJ), em Ilha Grande, os interessados podem frequentar cursos e ganhar um certificado ao final que os autoriza a criar jataís e os credencia a se tornarem monitores. A respeito disso considera-se que:

Só é permitida a criação com autorização da universidade. Assim, temos segurança de que os criadores estão seguindo a nossa filosofia, de que a importância das abelhas não é só o mel, mas sua função polinizadora, após um ano, 14 pessoas se formaram nas escolas. A ideia é expandir o projeto na ilha, abranger toda a Costa Verde fluminense e envolver um número cada vez maior de interessados. (ROMALHO, 2006)

O sucesso da atividade, tem exemplos pontuais, para interessados na criação de abelhas em áreas urbanas, mediante a cuidados especiais, conforme detalhados por Menezes (2017), que ainda ressalta a criação de abelhas sem ferrão em áreas urbanas pode ser uma atividade prazerosa, ajudando a preservar o meio ambiente, estimulando a educação ambiental e incentivando a população a entender a importância desses insetos na produção de alimentos.

\section{CONCLUSÕES}

Este estudo permitiu uma avaliação preliminar dos níveis de $\mathrm{NO}_{2}$ na cidade do Rio de Janeiro e uma atenção referente aos seus possíveis impactos sobre as suas extensas áreas verdes, e apesar de os valores de concentração de $\mathrm{NO}_{2}$ observados não serem superiores aos já comprovados como perturbadores ao processo de polinização das, acredita-se que a exposição prolongada e crônica a este poluente pode implicar em outros impactos a esse processo, ainda que menos severos, contaminantes de $\mathrm{No}_{\mathrm{x}}$ podem impactar no processo de polinização das abelhas.

Através desse estudo ainda foi possível perceber a grande lacuna de conhecimento e dados em relação a influência direta dos poluentes atmosféricos sobre flora, o processo de polinização e o declínio da população das abelhas. Além disso, a maioria dos artigos publicados nos últimos 5 anos no Brasil, acerca do tema 'declínio da população de abelhas' são associados, majoritariamente, apenas ao uso indiscriminado de agrotóxicos, mesmo que outros estudos, bem como o presente trabalho, indiquem a possibilidade de outros fatores influenciarem no desaparecimento e migração das abelhas que habitam em ambientes urbanos.

Deste modo, é necessário que existam estudos abordando a temática comportamental da polinização de abelhas em flores expostas aos contaminantes advindos de óxidos de nitrogênio $\left(\mathrm{NO}_{\mathrm{x}}\right)$, ou seja, mapear a incidência dessas abelhas e de determinadas flores, na cidade Rio de Janeiro, a fim de garantir prevenção e proteção adequada aos agravos causados por esses contaminantes.

\section{REFERÊNCIAS}

AFEEVAS. Associação dos Fabricantes de Equipamentos para Controle de Emissões Veiculares da América do Sul. Conheça as tecnologias de suporte ao combate nas emissões de nox. São Paulo: AFEEVAS, 2016.
APREMAVI. Flora muitas espécies da flora da Mata Atlântica são endêmicas e ameaçadas de extinção. Santa Catarina: Copyright, 2020.

ARAÚJO, C.. Mata Atlântica: o bioma do Rio de Janeiro. Rio 
de Janeiro: Multirio, 2015.

BUCHMANN, S. L.; NABHAN, G. P.. The forgotten pollinators. Washington: Island Press [for] Shearwater Books, 1996.

CETESB. Companhia Ambiental do Estado de São Paulo. Efeitos da poluição atmosférica na vegetação. São Paulo: GOV, 2020.

CÓNSUL, M. D.; THIELE, D.; VESES, R. C.; BAIBICH, I. M.; DALLAGO, R. M.. Decomposição catalítica de óxidos de nitrogênio. Química Nova, São Paulo, v.27, n.3, 2004.

CGEE. Importância dos polinizadores na produção de alimentos e na segurança alimentar global. Brasília: Centro de Gestão e Estudos Estratégicos, 2017.

DANTAS, G.; SICILIANO, B.; FRANÇA, B. B.; SILVA, C. M.; ARBILLA, G.. The impact of COVID-19 partial lockdown on the air quality of the city of Rio de Janeiro, Brazil. Science of the Total Environment, v.729, p.139085, 2020. DOI: http://doi.org/10.1016/i.scitotenv.2020.139085

DEL CLARO K.; SILINGARDI, H. M. T.. Ecologia das Interações Plantas-Animais: uma abordagem ecológica evolutiva. Rio de Janeiro: Technical Books, 2012.

ECYCLE. Óxidos de nitrogênio: o que são os NOx e quais seus impactos. São Paulo: Copyright, 2020.

FAEGRI, K.; VAN DER PIJL, L.. The principies of pollination ecology. 3 ed. Oxford: Pergamon, 1979.

FEMERJ. Plano de Manejo do Parque Estadual da Pedra Branca - PEPB. Rio de Janeiro: Planos de Manejo, 2020.

FREITAS, B. M.; SILVA, C. I.. Agricultura e Polinizadores. São Paulo: Associação Brasileira de Estudos das Abelhas, 2015.

FREITAS, W. R. S.; JABBOUR, C. J. C.. Utilizando estudo de caso (s) como estratégia de pesquisa qualitativa: boas práticas e sugestões. Revista Estudo \& Debate, Lajeado, v.18, n.2, p.07-22, 2011

FROTA, E. B.; VASCONCELOS, N. M. S.. Química Ambiental. 2 ed. Fortaleza: Universidade Estadual do Ceará, 2019.

GIRLING, R. D.; LUSEBRINK, I.; FARTHING, E.; NEWMAN, T. A.; POPPY, G. M.. Diesel exhaust rapidly degrades floral odours used by honeybees. Scientific Reports, n.2779, p.1-5, 2013. DOI: http://doi.org/10.1038/srep02779

GULLAN, P. J.; GRANSTON, P. S.. Os insetos: um resumo de entomologia. São Paulo: Roca, 2007.

GRANDA, A.. Jardim Botânico do Rio inaugura projeto de criação de abelhas sem ferrão. Rio de Janeiro: Agência Brasil, 2016.

IBASE. Parque Nacional da Tijuca: Integrando proteção ambiental e participação social em áreas urbanas. Rio de Janeiro: Programa Petrobrás Ambiental, 2006.

IBGE. Instituto Brasileiro de Geografia e Estatística. Cidades: Rio de Janeiro - Rio de Janeiro. Rio de Janeiro: IBGE, 2019.

IBGE. Instituto Brasileiro de Geografia e Estatística. Cidades:
Rio de Janeiro - Rio de Janeiro - Frota de Veículos ano 2018. Rio de Janeiro: Ministério da Infraestrutura/DENATRAN, 2018.

KEARNS, C. A.; INOUYE, D. W.. Techniques for pollination biologists. Boulder: University Press of Colorado, Niwot, 1993.

KLINKHAMER, P. G. L.; JONG, T. L.; METZ, J. A. J.. Why plants can be too attractive - a discussion of measures to estimate male fitness. Journal of Ecology, n.82, p.191-194, 1994. DOI: http://doi.org/10.2307/2261399

LORENZON, M. C.. Projeto incentiva criação artesanal de abelhas como opção sustentável. Campina Grande: Assessoria de imprensa UFCG, 2006.

MAIA, J. L. M.; NETTO, V. M.; COSTA, B. L. G.. Forma urbana e poluição atmosférica: impactos na cidade do Rio de Janeiro. Revista Brasileira de Gestão Urbana, Curitiba, v.11, 2019.

MACEDO, R.. Poluente no Rio está três vezes acima do tolerado pela OMS. Rio de Janeiro: Vida \& Ação, 2018.

MEIRELLES FILHO, J.. A Revolução das Abelhas sem Ferrão. São Paulo: Página 22, 2017.

MENEZES, C.. Criar abelhas em áreas urbanas preserva o meio ambiente. Brasília: Embrapa, 2017.

MINAS GERAIS. O NOx, um contaminante atmosférico, e o CO2, um gás de efeito estufa. Belo Horizonte: Estado de Minas Internacional, 2015.

MOORE, D.. Honey bee circadian clocks: behavioral control from individual workers to whole-colony rhytms. Journal of Insects Physiology, Johnson, v.47, p.843-857, 2001. DOI: http://doi.org/10.1016/S0022-1910(01)00057-9

MORALES, M. N.; KÖHLER, A.. Comunidade de Syrphidae (Díptera): diversidade e preferências florais no Cinturão Verde (Santa Cruz do Sul, RS, Brasil). Revista Brasileira Entomologia, Curitiba, v.52, p.41-49, 2008.

NASCIMENTO, W. M.; GOMES, E. M. L.; BATISTA, E. A.; FREITAS, R. A.. Utilização de agentes polinizadores na produção de sementes de cenoura e pimenta doce em cultivo protegido. Hortic. Bras., Vitoria da Conquista, v.30, n.3, p.494-498, 2012.

NUCCI, M.. Biologia Floral, Fenologia Reprodutiva, Entomofauna e Valor Econômico dos Serviços Ecossistêmicos Realizados pelos Polinizadores de Campomanesia Adamantium (Cambessédes) O. Berg Myrtaceae em área de Cerrado no Sul do Mato Grosso do Sul - Brasil. Tese (Doutorado em Entomologia e Conservação da Biodiversidade) - Universidade Federal da Grande Dourados, Mato Grosso do Sul, 2016.

PEDREIRA, L. O. L.; ANDRADE, F. N.; BRASILIANO, V. F.. Nota Técnica $n^{\circ} 37$ Índices de Áreas Verdes do Município do Rio de Janeiro. Rio de Janeiro: Prefeitura do Rio de Janeiro, 2017. DOI: http://doi.org/10.13140/RG.2.2.19062.29764

PEDROSO, A. N. V.. Poluentes Atmosféricos \& Plantas Bioindicadoras. São Paulo: Instituto de Botânica, 2007. 
PEREIRA, M. G.; GALVÃO, T. F.. Etapas de busca e seleção de artigos em revisões sistemáticas da literatura. Epidemiologia e Serviços de Saúde, Brasília, v.23, p.369-371, 2014.

RAMALHO, M.. Projeto incentiva criação de abelhas como opção sustentável. Rio de Janeiro: FAPERJ, 2006.

RECH, A. R.; AGOSTINI, K.; OLIVEIRA, P. E.; MACHADO, I. C.. Biologia da Polinização. Rio de Janeiro: Projeto Cultural, 2014.

ROUBIK, D. W.. Ecology and natural history of tropical bees. New York: Cambridge University Press, 1989.

SAUNDERS, D. S.. Insect Clocks. Oxford: Pergamon Press, 1982.

SICILIANO, B.; DANTAS, G.; SILVA, C.; ARBILLA, G.. The Updated Brazilian National Air Quality Standards: a Critical Review. Journal of the Brazilian Chemical Society, São Paulo, v.31, p.523-535, 2020. DOI: http://doi.org/10.21577/0103-5053.20190212

SILVA, C. M.; ARBILLA, G.. Urbanization and the challenges in the characterization of air quality. Revista Virtual de Química, Niterói, v.10, p.1898-1914, 2018.

SILVEIRA, F. A.; MELO, G. A. R.; ALMEIDA, E. A. B.. Abelhas brasileiras: sistemática e identificação. Belo Horizonte: Ministério do Meio Ambiente, 2002.
SIMPSON, B. B.; NEFF, J. L.. Floral rewards: alternatives to pollen and neclar. Missouri, Annals of the Missouri Botanical Garden, n.68, p.301-322, 1981. DOI: http://doi.org/10.2307/2398800

UGUCIONE, C.; MACHADO, C.; MELLO, D.; CARDOSO, A. A. Avaliação de NO2 na atmosfera de ambientes externos e internos na cidade de Araraquara, São Paulo, Química Nova, v.32, n.7, 2009

VENTURIERI, G. C.; VASCONCELOS, M. A. M.; OLIVEIRA, P. S.; MATTIETTO, R. A.. Caracterização, colheita, conservação e embalagem de méis de abelhas indígenas sem ferrão. Belém: Embrapa, 2007.

WILLIAMS, N. H.; DODSON, C. H.. Seletive attraction of male euglossine bees to orchid floral fragances and its importance in long distance pollen flow. Missouri. Society for the Study of Evolution, n.26, p.84-95, 1972. DOI: http://doi.org/10.1111/j.1558-5646.1972.tb00176.x

WOLOWSKI, M.; AGOSTINI, K.; RECH, A. R.; VARASSIN, I. G.; MAUÉS, M.; FREITAS, L.; CARNEIRO, L. T.; BUENO, R. O.; CONSOLARO, H.; CARVALHEIRO, L.; SARAIVA, A. M.; SILVA, C. I.. Relatório temático sobre polinização, polinizadores e produção de alimentos no Brasil. São Carlos: Cubo, 2019.

ZATELLI, K. S.. Qual a importância das abelhas na manutenção dos ecossistemas?. Viçosa: Matanativa, 2019.

A CBPC - Companhia Brasileira de Produção Científica (CNPJ: 11.221.422/0001-03) detém os direitos materiais desta publicação. Os direitos referem-se à publicação do trabalho em qualquer parte do mundo, incluindo os direitos às renovaç̃ões, expansões e disseminações da contribuiç̃o, bem como outros direitos subsidiários. Todos os trabalhos publicados eletronicamente poderão posteriormente ser publicados em coletâneas impressas sob coordenação da Sustenere Publishing, da Companhia Brasileira de Produção Científica e seus parceiros autorizados. Os (as) autores (as) preservam os direitos autorais, mas não têm permissão para a publicação da contribuição em outro meio, impresso ou digital, em português ou em tradução. 